\title{
Immunoexpression of lactoferrin in bone metastases and corresponding primary carcinomas
}

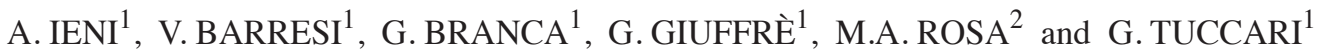 \\ ${ }^{1}$ Department of Human Pathology, Section of Pathological Anatomy; ${ }^{2}$ Department of Surgical Specialties, \\ Section of Oncological Orthopaedics, University of Messina, Messina, Italy
}

Received September 19, 2012; Accepted December 11, 2012

DOI: $10.3892 / \mathrm{ol} .2013 .1227$

\begin{abstract}
Although the immunohistochemical presence of lactoferrin (LF) in pathological neoplastic bone and cartilage samples has previously been studied, no data concerning the distribution of LF in bone metastases of cancers that have originated from different organs are available at present. Consequently, using a monoclonal antibody, we have investigated the immunohistochemical LF pattern in 50 formalin-fixed and paraffin-embedded samples of human bone metastases and their corresponding primary carcinoma tumours (breast, 8; prostate, 4; kidney, 4; lung, 3; colon-rectum, 2 and uterus, 4). Quantification of LF immunoreactivity was performed using an intensity distribution (ID) score. LF immunostaining with a variable ID score was encountered in 11/25 (44\%) metastatic lesions. In particular, the LF immunoreactivity was identified with a percentage ranging from 50 to $75 \%$ of bone metastases due to prostatic, renal, uterine and colorectal carcinomas; the positivity decreased in breast carcinomas (37.5\%) and was completely absent in lung cancers. No differences in the LF-ID score were observed between primary and metastatic neoplastic localisations. Additionally, no correlations were identified between LF immunoexpression and the other parameters tested, including the age and gender of patients. Regardless of the mechanism of action of LF in human malignant tumours, we identified LF immunohistochemical reproducibility at primary and metastatic sites. Therefore, we hypothesise that the presence of LF in native neoplastic carcinomatous clones is maintained in secondary bone metastatic deposits.
\end{abstract}

\section{Introduction}

Lactoferrin (LF) is a single-chain non-haeme iron-binding glycoprotein with a molecular weight of $\sim 80 \mathrm{kDa}$, consisting

Correspondence to: Professor Giovanni Tuccari, Department of Human Pathology, Section of Pathological Anatomy, Azienda Ospedaliera Universitaria 'Policlinico G. Martino', Via Consolare Valeria 1, I-98125 Messina, Italy

E-mail: tuccari@unime.it; giovannituccari@yahoo.it

Key words: immunohistochemistry, lactoferrin, bone tissue, metastasis, carcinoma of 700 amino acids with a high degree of homology between species (1). The concentration of LF is high in milk, mainly in colostrum, although it has been found in other body fluids and secretions such as blood plasma, tears, saliva, urine, bile, semen and amniotic fluid (2-4).

LF has a wide range of biological activities, including antimicrobial properties, improvement of iron status, anti-inflammation, development of immune function and promotion of cell proliferation during carcinogenesis $(5,6)$.

Using immunohistochemistry, the distribution of LF has been investigated in normal human fetal and adult tissues including the stomach, kidney, lung, pancreas, liver, bone marrow and skin $(7,8)$. More recently, the immunohistochemical distribution of LF has been analysed in human embryonic, fetal and adult bone and cartilaginous tissues (9), in order to investigate whether LF may be involved in the growth and differentiation of the human skeleton, similar to that suggested in murine models as well as in cell culture lines (10-12). In addition, our research group has also evaluated the immunohistochemical presence of LF in pathological neoplastic bone and cartilage samples $(13,14)$. LF immunoreactivity was revealed in chondroblastomas, chondromyxoid fibromas, giant cell tumours, osteoid osteomas, myelomas and adamantinomas; while no LF immunoexpression was detected in enchondromas, osteochondromas, ossifying fibromas, chondrosarcomas or osteosarcomas (13-15).

As no data regarding the distribution of LF in bone metastases of cancers that have originated from different organs are available at present, we set out to analyse the immunohistochemical pattern of LF in a cohort of these samples as well as in the corresponding primary neoplasms using a monoclonal antibody against LF.

\section{Materials and methods}

Specimens. LF immunoexpression was investigated in 25 specimens of human bone metastatic lesions obtained through curettage or surgery from an equal number of patients (16 females, 9 males; mean ages, 64 and 92 years, respectively; age range, 28-85 years). Data concerning the site of occurrence of the metastases as well as surgical samples of the primary corresponding carcinomas were obtained from the files at the Department of Human Pathology, University of Messina, Messina, Italy. The primary carcinoma sites included breast 
Table I. Clinicopathological and LF immunohistochemical data concerning bone metastases.

\begin{tabular}{|c|c|c|c|c|c|c|c|c|c|}
\hline $\begin{array}{l}\text { Case } \\
\text { no. }\end{array}$ & Gender & Age & $\begin{array}{l}\text { Primary site } \\
\text { of neoplasms }\end{array}$ & $\begin{array}{c}\text { Histotype of } \\
\text { carcinoma }\end{array}$ & Grading & $\begin{array}{l}\text { Site of bone } \\
\text { metastases }\end{array}$ & LF-ASP & LF-IS & $\begin{array}{l}\text { LF-ID } \\
\text { score }\end{array}$ \\
\hline 1 & $\mathrm{~F}$ & 58 & Breast & Medullary & - & Femur & 0 & 0 & 0 \\
\hline 2 & $\mathrm{M}$ & 59 & Prostate & Cribriform & $\mathrm{G} 2$ & Femur & 1 & 2 & 2 \\
\hline 3 & $\mathrm{~F}$ & 54 & Breast & Ductal invasive & G3 & Humerus & 0 & 0 & 0 \\
\hline 4 & $\mathrm{~F}$ & 80 & Breast & Ductal invasive & G2 & Femur & 2 & 1 & 2 \\
\hline 5 & $\mathrm{~F}$ & 28 & Uterus & Endometrioid & G2 & Vertebra & 2 & 2 & 4 \\
\hline 6 & $\mathrm{~F}$ & 80 & Colon-rectum & Adenocarcinoma & G2 & Femur & 1 & 2 & 2 \\
\hline 7 & $\mathrm{~F}$ & 55 & Breast & Ductal invasive & G2 & Femur & 1 & 2 & 2 \\
\hline 8 & M & 56 & Lung & Small cell & - & Sternum & 0 & 0 & 0 \\
\hline 9 & $\mathrm{~F}$ & 70 & Lung & Adenocarcinoma & G3 & Femur & 0 & 0 & 0 \\
\hline 10 & $\mathrm{~F}$ & 60 & Breast & Lobular invasive & - & Femur & 0 & 0 & 0 \\
\hline 11 & M & 61 & Lung & Small cell & - & Fibula & 0 & 0 & 0 \\
\hline 12 & M & 74 & Kidney & Clear cell & G2 & Femur & 0 & 0 & 0 \\
\hline 13 & $\mathrm{~F}$ & 69 & Uterus & Serous & G3 & Humerus & 0 & 0 & 0 \\
\hline 14 & $\mathrm{~F}$ & 62 & Breast & Ductal invasive & G1 & Vertebra & 2 & 2 & 4 \\
\hline 15 & $\mathrm{~F}$ & 69 & Colon-rectum & Adenocarcinoma & G3 & Femur & 0 & 0 & 0 \\
\hline 16 & $\mathrm{~F}$ & 76 & Uterus & Endometrioid & G2 & Femur & 1 & 1 & 1 \\
\hline 17 & M & 75 & Prostate & Undifferentiated & G3 & Pelvis & 0 & 0 & 0 \\
\hline 18 & $\mathrm{~F}$ & 75 & Breast & Ductal invasive & G3 & Vertebra & 0 & 0 & 0 \\
\hline 19 & M & 70 & Kidney & Chromophobe & G2 & Femur & 2 & 2 & 4 \\
\hline 20 & M & 85 & Prostate & Adenocarcinoma & G1 & Vertebra & 2 & 2 & 4 \\
\hline 21 & $\mathrm{~F}$ & 58 & Kidney & Clear cell & $\mathrm{G} 2$ & Vertebra & 1 & 1 & 1 \\
\hline 22 & M & 71 & Prostate & Adenocarcinoma & G2 & Femur & 1 & 2 & 2 \\
\hline 23 & $\mathrm{~F}$ & 52 & Breast & Lobular invasive & - & Femur & 0 & 0 & 0 \\
\hline 24 & $\mathrm{~F}$ & 67 & Uterus & Non-endometrioid & G3 & Pelvis & 0 & 0 & 0 \\
\hline 25 & M & 59 & Kidney & Clear cell & G3 & Fibula & 0 & 0 & 0 \\
\hline
\end{tabular}

LF, lactoferrin; ASP, area of staining positivity; IS, intensity of staining; ID, intensity distribution.

( 8 cases), prostate (4 cases), kidney (4 cases), lung (3 cases), colon-rectum ( 2 cases) and uterus (4 cases).

Preparation of specimens. All samples were fixed in $10 \%$ neutral formalin for 24-36 h at room temperature (RT), and then embedded in paraffin at $56^{\circ} \mathrm{C}$. The bone metastatic specimens were subjected to a decalcification procedure performed using formic acid (5\%) or ethylenediamine-tetraacetic acid (EDTA; 5\%, pH 7.4) for $\leq 12-24 \mathrm{~h}$, depending on the size of mineralised samples. From each tissue block, 4- $\mu \mathrm{m}$ sections were stained with haematoxylin and eosin (H\&E) for microscopic evaluation. Parallel sections were cut and mounted on silane-coated glass, then dewaxed in xylene and rehydrated in graded ethanols. Antigen retrieval was performed prior to the addition of the primary antibody, by heating slides placed in $0.01 \mathrm{M}$ citrate buffer at $\mathrm{pH} 6.0 \mathrm{in}$ a microwave oven $(750 \mathrm{~W})$ for three 5-min cycles.

Immunohistochemistry. For the immunohistochemical study, sections were treated in a moist chamber with: i) $0.1 \% \mathrm{H}_{2} \mathrm{O}_{2}$ in methanol for $30 \mathrm{~min}$ at RT, to block the intrinsic peroxidase activity; ii) normal sheep serum to prevent non-specific adherence of serum proteins; iii) mouse monoclonal primary antibody (anti-human) against LF [clone 1A1; working dilution (wd), 1:75; Biodesign International, Inc., Saco, ME, USA] for 60 min at RT; iv) sheep anti-mouse immunoglobulin antiserum (wd, 1:25; Behring Institute, Marburg, Germany) for $30 \mathrm{~min}$ at RT; v) mouse anti-horseradish peroxidase-antiperoxidase complexes (wd, 1:25; DakoCytomation, Copenhagen, Denmark) for $30 \mathrm{~min}$ at RT. To reveal peroxidase activity, the sections were incubated in the dark for $10 \mathrm{~min}$ with $100 \mathrm{mg}$ 3,3'-diaminobenzidine tetrahydrochloride (Sigma, St. Louis, MO, USA) in $200 \mathrm{ml} 0.03 \%$ hydrogen peroxide in phosphate-buffered saline (PBS) solution. The nuclear counterstaining was performed using Mayer's haemalum solution.

Renal tubular structures within normal kidney samples and portions of the parotid gland were utilised as LF-positive controls. In addition, the LF immunoreactivity demonstrated in granules of polymorphonuclear neutrophils inside the neoplastic lesions was utilised as additional positive control. Finally, to test the inter-run variability of LF immunostaining, the same LF-positive parotid sample was utilised in every run. To test the of LF immunoreaction in order to omit the possibility of non-specific reaction, serial sections of each affected specimen were tested by replacing the specific antiserum with either PBS, normal rabbit serum, or by absorption with 


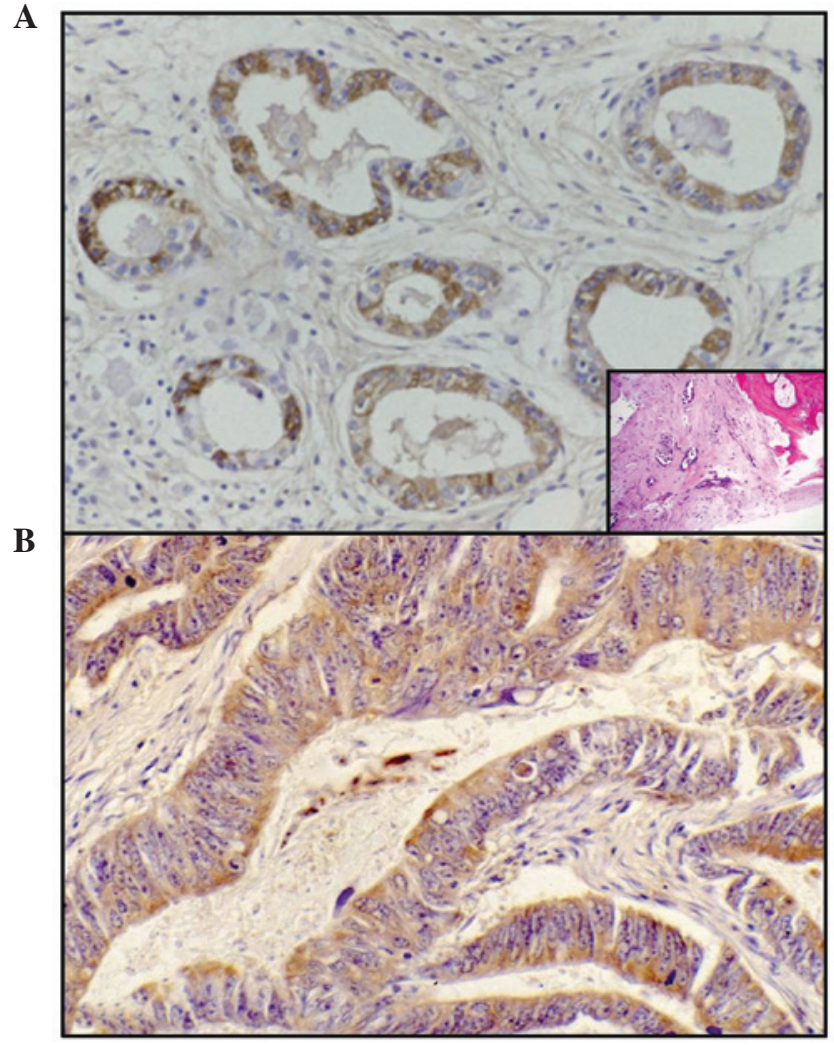

Figure 1. (A) At greater magnification LF immunoreactivity is evident in certain prostatic elements close to others that are unreactive, localised inside the bone tissue (original magnification, x160). The inset reveals the corresponding haematoxylin and eosin routinely stained section of the bone metastatic site (original magnification, $\mathrm{x} 40$ ). (B) A diffuse LF immunostaining is demonstrated in the neoplastic uterine glands (original magnification, x300).

an excess of purified human LF from human liver and spleen (Sigma) as well as with pre-absorbed primary antibody; the results obtained were negative.

Microscopy. The analysis of immunostained sections was estimated by light microscopy using x 20 and $\times 40$ objective lenses and a $\times 10$ eyepiece. Two pathologists used a double-headed microscope to perform the assessment of LF immunostained sections on a consensus basis. The percentage of stained neoplastic cells (area of staining positivity, ASP) was graded as follows: 0 , no staining; $1,>0-5 \% ; 2,>5-50 \%$ and $3,>50 \%$. The intensity of staining (IS; weak, 1; moderate, 2; strong, 3) was also assessed. Then an LF intensity distribution (ID) score was calculated for each case by multiplying the values of the ASP and the IS, according to that described by Tuccari et al (16).

Statistical analysis. The correlations between LF immunoexpression and the clinical data (age and gender of patients and site of the lesion) were investigated using either the $\chi^{2}$ or the Fisher's exact test, as appropriate. Moreover, the correlation between the LF immunoreactivity pattern in primary carcinomas and the corresponding metastatic bone samples was analysed by a Spearman's rank correlation test. $\mathrm{P}<0.05$ was considered to indicate a statistically significant difference. Data were analysed using the Statistical Package for the Social Sciences (SPSS) software, version 6.1.3 (SPSS, Inc., Chicago, IL, USA).

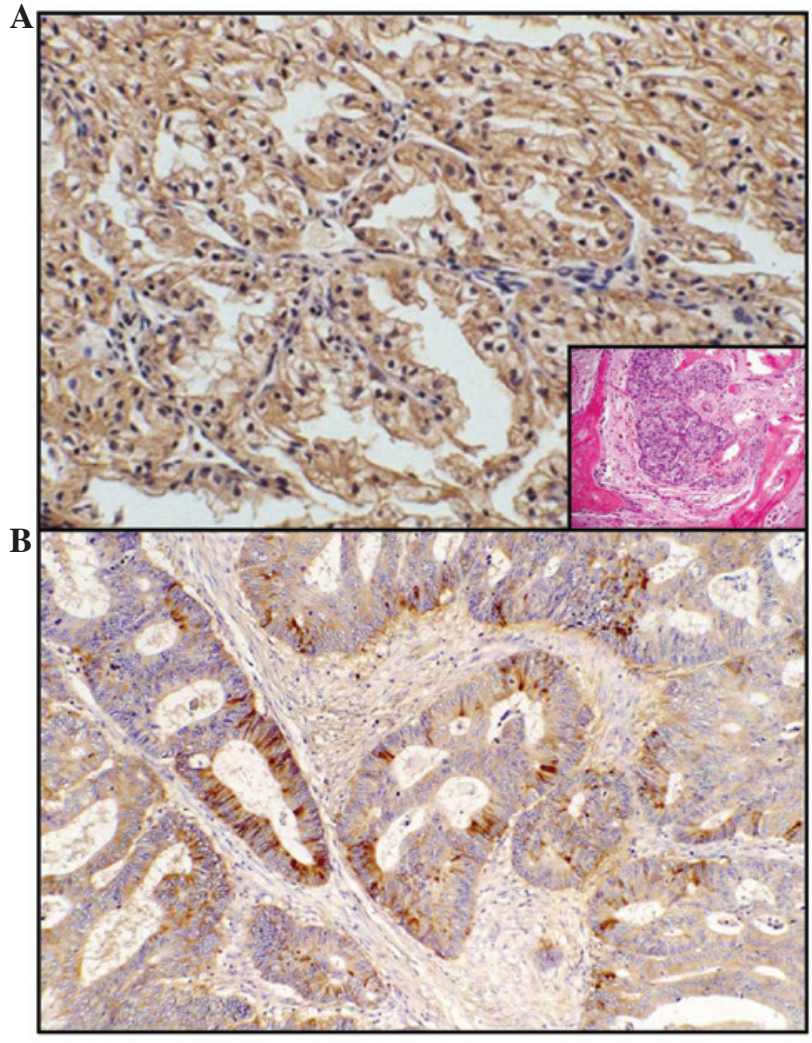

Figure 2. (A) LF cytoplasmic positivity is evident at the periphery of clear cells of renal carcinoma metastatic to bone (original magnification, $\mathrm{x} 200$ ). The inset illustrates the corresponding haematoxylin and eosin routinely stained section of the bone metastatic site (original magnification, $\mathrm{x} 40$ ). (B) Immunoreactive colonic cells are in contact with negative cells inside the bone neoplastic deposits (original magnification, x240).

\section{Results}

Routinely stained H\&E sections exhibited a good morphology, confirming the histopathological diagnosis of all cases, either in the primary neoplastic lesions or in the bone neoplastic deposits. Clinicopathological and immunohistochemical data for LF relative to the 25 analysed bone metastatic samples as well as the corresponding primary carcinomas are listed in Table I.

LF immunostaining with a variable ID score was encountered in 11/25 (44\%) metastatic lesions; LF was identified in $7 / 16(43.8 \%)$ female and 4/9 (44.4\%) male patients. In particular, LF immunoreactivity was identified with a percentage ranging from 50 to $75 \%$ of the cases of bone metastases due to prostatic (Fig. 1A, inset), uterine (Fig. 1B), renal (Fig. 2A, inset) and colorectal (Fig. 2B) carcinomas (Table I). Additionally, the positivity was decreased in breast carcinomas (37.5\%) and was completely absent in lung cancers (Table I). The immunostaining was mainly localised in the cytoplasm of the neoplastic elements and occasionally in the nuclei of the same cells. No differences in LF-ID score were observed between the primary and metastatic neoplastic localisations with an equivalent LF immunoreactivity, either regarding the intensity or the percentage of stained cells.

LF was evident in renal tubular structures, parotid ductular/acinar portions and in granules of polymorphonuclear neutrophils utilised as positive controls. 
No correlations were observed between LF immunoexpression and the other parameters investiaged, including the age and gender of the patients and the localisation of neoplastic metastatic lesions in bones.

\section{Discussion}

A number of studies have demonstrated promising results in the potential use of LF for the improvement of bone health (12,17-20). In particular, LF stimulates the proliferation, differentiation and survival of osteoblasts (20), as well as significantly increasing the mineral apposition rate and bone formation, as demonstrated by the assessment of dynamic histomorphometric indices (12). Consequently, it has been suggested that LF may be useful in pathological states of reduced bone density when used either systemically or locally.

As part of a series of studies concerning the immunohistochemical distribution pattern of LF in human neoplasms (21), we have previously investigated this distribution in pathological primary neoplastic bone and cartilage samples, as well as in the corresponding human normal embryo-fetal bone and cartilage tissues $(9,13)$. The observed heterogeneous distribution of LF in tumours, as well as its independence from benign and malignant characteristics, appear to contrast with the elsewhere hypothesised role of LF as oncofetal marker (15). The most aggressive bone tumours, such as osteosarcomas and chondrosarcomas, were consistently observed to be unreactive for LF; while the pattern of LF expression was mainly evident in the early phases of bone growth, suggesting an important role for LF as a bone growth regulator in the early phases of skeletal development, particularly in endochondral ossification $(12,15)$.

Metastatic deposits in bones from carcinomas arising from breast, colon, endometrium, kidney, lung and prostate are considered to be a key stage in the natural history of these neoplasms, although to date no data regarding the immunohistochemical distribution of LF have been available in the literature. In the current study, we immunohistochemically detected a variable ID score for LF in the cytoplasm of 11/25 (44\%) metastatic neoplastic bone lesions as well as in the corresponding primary carcinomas. Occasionally, the site of LF immunostaining was appreciable both in the nucleus and cytoplasm, and this co-localisation was expected, as LF has also been revealed in the nucleoli and LF is speculated to be involved in ribosomal biogenesis $(21,22)$. With regard to the site of the primary carcinomas, LF immunoreactivity was found with a percentage ranging from 50 to $75 \%$ of bone metastases due to colorectal, uterine, prostatic and renal carcinomas. In addition, the positivity was decreased in breast carcinomas (37.5\%) and was completely absent in lung cancers. In these primary neoplastic conditions, previous studies by our research group have demonstrated a similar variable percentage of immunoexpression of LF (23-26). In detail, a progressive increase of LF immunostaining was encountered when moving from endometrial adenocarcinomas (61\%) (25) and renal cell carcinomas (62.5\%) (26) to well-differentiated prostatic adenocarcinomas (66\%) (23), and finally to adenocarcinomas and colloid colorectal carcinomas (80\%) (24). The most likely explanation for the negative LF immunoreactivity observed in a number of cases of the above mentioned cohorts of tumours has been correlated with undifferentiated or less differentiated variants of carcinomas (23-26). Occasional and slight LF staining has been found in isolated cells of undifferentiated prostatic carcinomas (23), while only well- and moderately differentiated colonic carcinomas exhibited a strong LF reaction. Furthermore, a significantly higher LF-ID score was evident in the endometrioid type in comparison to the non-endometrioid type carcinomas of the uterus (25). In addition, significant differences in the LF-ID score were found among clear cell renal carcinomas (CCC) and other non-CCC variants, the former exhibited a lower score (26). By contrast, the positive rate of LF in breast carcinoma has been identified with a large variability, ranging from 7.5 to $42 \%$ of cases $(27,28)$. However, LF was more often observed in low-grade ductal carcinomas with positive estrogen/progesterone receptors, confirming a decrease in LF immunostaining in less differentiated and more aggressive breast carcinomas (27-29). Therefore, LF may be a potential marker for glandular or acinar differentiation, similar to that previously observed in other malignancies $(28,30,31)$. No data concerning LF immunodistribution in primary and metastatic lung cancer are currently available in literature.

The origin of LF in human malignant primary and metastatic tumours has not yet been fully elucidated. It is well known that LF has a high affinity for iron, which is considered to be an essential nutrient for cells that are dividing rapidly, such as tumour cells, taking part in various metabolic processes (including oxydative phosphorylation and RNA/DNA synthesis) $(32,33)$. Therefore, neoplastic elements may produce LF in order to provide a greater amount of iron available for their turnover, as we have previously suggested $(21,24,26,34,35)$. Alternatively, the localisation of LF in malignant cells may not reflect an intracellular synthesis, but rather the degree of transmembranous iron transfer as the consequence of defective or functionally impaired LF-receptors already documented on the surface of target cells as well as in human neoplastic cell lines $(36,37)$. It has been suggested that $\mathrm{LF}$ is involved in the regulation of certain important processes, such as the cell cycle and cell death, resistance to carcinogenesis and the development of metastases $(26,38)$. Other potential mechanisms have also been suggested with regard to the role of LF in the process of human carcinogenesis. These include induction of programmed cell death, prevention of angiogenesis and regulation of cell cycle protein expression $(39,40)$. LF is able to trigger the apoptotic process by the activation of caspase- 3 and -8 as well as the FAS signaling pathway $(41,42)$. By contrast, LF has also been demonstrated to inhibit tumour-initiated angiogenesis in vitro and in vivo, possibly by blocking endothelial function and inducing IL-18 production $(39,43,44)$. In addition, it has been demonstrated that LF promoted growth arrest either at the G1-S transition in breast cancer cells (43) as well as at the G0-G1 checkpoint in oral and neck cancer cells (44). However, regardless of the mechanism of action of LF in human malignant tumours, we have identified LF immunohistochemical reproducibility at primary and metastatic sites. Therefore, we hypothesise that the appearance of LF in native neoplastic carcinomatous 
clones is maintained in secondary bone metastatic deposits. However, additional investigations are required, mainly regarding the potential for new applications of LF in cancer treatment, due to its nutraceutical function and its ability to potentiate chemotherapy.

\section{References}

1. González-Chávez SA, Arévalo-Gallegos S and Rascón-Cruz Q: Lactoferrin: structure, function and applications. Int J Antimicrob Agents 33: 301.e1-e8, 2009.

2. Steijns JM and van Hooijdonk AC: Occurrence, structure, biochemical properties and technological characteristics of lactoferrin. Br J Nutr 84 (Suppl 1): S11-S17, 2000.

3. van der Strate BW, Beljaars L, Molema G, Harmsen MC and Meijer DK: Antiviral activities of lactoferrin. Antiviral Res 52: 225-239, 2001

4. Öztas Yeșim ER and Özgünes N: Lactoferrin: a multifunctional protein. Adv Mol Med 1: 149-154, 2005.

5. Pierce A, Legrand D and Mazurier J: Lactoferrin: a multifunctional protein. Med Sci 25: 361-369, 2009.

6. de Mejia EG and Dia VP: The role of nutraceutical proteins and peptides in apoptosis, angiogenesis, and metastasis of cancer cells. Cancer Metastasis Rev 29: 511-528, 2010.

7. Mason DY and Taylor CR: Distribution of transferrin, ferritin, and lactoferrin in human tissues. J Clin Pathol 31: 316-327, 1978.

8. Reitamo S, Konttinen YT, Dodd S and Adinolfi M: Distribution of lactoferrin in human fetal tissues. Acta Paediatr Scand 70 395-398, 1981

9. Ieni A, Barresi V, Grosso M and Tuccari G: Immunohistochemica evidence of lactoferrin in human embryo-fetal bone and cartilage tissues. Cell Biol Int 34: 845-849, 2010.

10. Cornish J: Lactoferrin promotes bone growth. Biometals 17: 331-335, 2004

11. Naot D, Grey A, Reid IR and Cornish J: Lactoferrin a novel bone growth factor. Clin Med Res 3: 93-101, 2005.

12. Cornish J and Naot D: Lactoferrin as an effector molecule in the skeleton. Biometals 23: 425-430, 2010.

13. Ieni A, Barresi V, Grosso M, Rosa MA and Tuccari G: Lactoferrin immuno-expression in human normal and neoplastic bone tissue. J Bone Miner Metab 27: 364-371, 2009.

14. Ieni A, Barresi V, Grosso M, Rosa MA and Tuccari G: Immunolocalization of lactoferrin in cartilage-forming neoplasms J Orthop Sci 14: 732-737, 2009.

15. Ieni A, Barresi V, Grosso M, Speciale G, Rosa MA and Tuccari G: Does lactoferrin behave as an immunohistochemical oncofetal marker in bone and cartilage human neoplasms? Pathol Oncol Res 17: 287-293, 2011.

16. Tuccari G, Villari D, Giuffrè G, Simone A, Squadrito G, Raimondo G and Barresi G: Immunohistochemical evidence of lactoferrin in hepatic biopsies of patients with viral or cryptogenetic chronic liver disease. Histol Histopathol 17: 1077-1083, 2002.

17. Blais A, Malet A, Mikogami T, Martin-Rouas C and Tomé D: Oral bovine lactoferrin improves bone status of ovariectomized mice. Am J Physiol Endocrinol Metab 296: 1281-1288, 2009.

18. Guo HY, Jiang L, Ibrahim SA, Zhang L, Zhang H, Zhang M and Ren FZ: Orally administered lactoferrin preserves bone mass and microarchitecture in ovariectomized rats. J Nutr 139 958-964, 2009

19. Takayama Y and Mizumachi K: Effect of lactoferrin-embedded collagen membrane on osteogenic differentiation of human osteoblast-like cells. J Biosci Bioeng 107: 191-195, 2009.

20. Naot D, Chhana A, Matthews BG, Callon KE, Tong PC, Lin JM, Costa JL, Watson M, Grey AB and Cornish J: Molecular mechanisms involved in the mitogenic effect of lactoferrin in osteoblasts. Bone 49: 217-224, 2011.

21. Tuccari G and Barresi G: Lactoferrin in human tumours: immunohistochemical investigations during more than 25 years. Biometals 24: 775-784, 2011.

22. Penco S, Scarfì S and Giovine M: Identification of an import signal for, and the nuclear localization of, human lactoferrin. Biotechnol Appl Biochem 34: 151-159, 2001.

23. Barresi $\mathrm{G}$ and Tuccari G: Lactoferrin in benign hypertrophy and carcinomas of the prostatic gland. Virchows Arch A Pathol Anat Histopathol 403: 59-66, 1984.
24. Tuccari G, Rizzo A, Crisafulli C and Barresi G: Iron-binding proteins in human colorectal adenomas and carcinomas: an immunocytochemical investigation. Histol Histopathol 7: 543-547, 1992.

25. Giuffrè G, Arena F, Scarfì R, Simone A, Todaro P and Tuccari G: Lactoferrin immunoexpression in endometrial carcinomas: relationships with sex steroid hormone receptors (ER and PR), proliferation indices (Ki-67 and AgNOR) and survival. Oncol Rep 16: 257-263, 2006.

26. Giuffrè G, Barresi V, Skliros C, Barresi G and Tuccari G: Immunoexpression of lactoferrin in human sporadic renal cell carcinomas. Oncol Rep 17: 1021-1026, 2007.

27. Wurster K, Heberling D and Rapp W: Carcinoembryogenic antigen (CEA) and lactoferrin (LF) in benign and malignant disease of the breast. A contribution to the immuno-histological demonstration of marker substances. Geburtshilfe Frauenheilkd 40: 412-422, 1980 (In German).

28. Charpin C, Lachard A, Pourreau-Schneider N, et al: Localization of lactoferrin and nonspecific cross-reacting antigen in human breast carcinomas. An immunohistochemical study using the avidin-biotin-peroxidase complex method. Cancer 55: 2612-2617, 1985.

29. Wrba F, Reiner A, Markis-Ritzinger E, Holzner JH, Reiner G and Spona J: Prognostic significance of immunohistochemical parameters in breast carcinomas. Pathol Res Pract 183: 277-283, 1988.

30. Caselitz J, Jaup T and Seifert G: Lactoferrin and lysozyme in carcinomas of the parotid gland. Virchows Arch A Pathol Anat Histol 394: 61-73, 1981.

31. Cabaret V, Vilain MO, Delobelle-Deroide A and Vanseymortier L: Immunohistochemical demonstration of ceruloplasmin and lactoferrin in a series of 59 thyroid tumors. Ann Pathol 12: 347-352, 1992 (In French).

32. Weinberg ED: Iron withholding: a defense against infection and neoplasia. Physiol Rev 64: 65-102, 1984.

33. Ye XY, Wang HX, Liu F and Ng TB: Ribonuclease, cell-free translation-inhibitory and superoxide radical scavenging activities of the iron-binding protein lactoferrin from bovine milk. Int J Biochem Cell Biol 32: 235-241, 2000.

34. Tuccari G, Rossiello R and Barresi G: Iron binding proteins in gallbladder carcinomas. An immunocytochemical investigation. Histol Histopathol 12: 671-676, 1997.

35. Tuccari G, Giuffrè G, Scarf R, Simone A, Todaro P and Barresi G: Immunolocalization of lactoferrin in surgically resected pigmented skin lesions. Eur J Histochem 49: 33-38, 2005.

36. Roiron D, Amouric M, Marvaldi J and Figarella C: Lactoferrinbinding sites at the syurface of HT29-D4 cells. Comparison with transferrin. Eur J Biochem 186: 367-373, 1989.

37. Suzuki YA, Lopez V and Lönnerdal B: Mammalian lactoferrin receptors: structure and function. Cell Mol Life Sci 62: 2560-2575, 2005.

38. Ward PP, Paz E and Conneely OM: Multifunctional roles of lactoferrin: a critical overview. Cell Mol Life Sci 62: 2540-2548, 2005.

39. Rodrigues L, Teixeira J, Schmitt F, Paulsson M and Månsson HL: Lactoferrin and cancer disease prevention. Crit Rev Food Sci Nutr 49: 203-217, 2009.

40. Fujita K, Matsuda E, Sekine K, Iigo M and Tsuda H: Lactoferrin enhances Fas expression and apoptosis in the colon muciosa of azoxymethane-treated rats. Carcinogenesis 25: 1961-1966, 2004.

41. Norrby K: Human apo-lactoferrin enhances angiogenesis mediated by vascular endothelial growth factor A in vivo. J Vasc Res 41: 293-304, 2004.

42. Shimamura M, Yamamoto $\mathrm{Y}$, Ashino $\mathrm{H}$, Oikawa $\mathrm{T}$, Hazato $\mathrm{T}$, Tsuda $\mathrm{H}$ and Iigo M: Bovine lactoferrin inhibits tumor induced angiogenesis. Int J Cancer 111: 111-116, 2004.

43. Damiens E, El Yazidi I, Mazurier J, et al: Lactoferrin inhibits G1 cyclin-dependent kinases during growth arrest of human breast carcinoma cells. J Cell Biochem 74: 486-498, 1999.

44. Xiao Y, Monitto CL, Minhas KM and Sidransky D: Lactoferrin down-regulates G1 cyclin-dependent kinases during growth arrest of head and neck cancer cells. Clin Cancer Res 10: 8683-8686, 2004. 